\title{
Models, Structures and Analogical Thinking in Early Childhood Education and Care and Primary School: A Qualitative Study on Teachers' Perception about Those Concepts
}

\author{
Francesca Granone1, Martin Stokke ${ }^{2}$ \\ ${ }^{1}$ Department of Early Childhood Education, University of Stavanger, Stavanger, Norway \\ ${ }^{2}$ Department of Teacher Education, Art and Culture, Nord University, Levanger, Norway \\ Email: francesca.granone@uis.no
}

How to cite this paper: Granone, F., \& Stokke, M. (2021). Models, Structures and Analogical Thinking in Early Childhood Education and Care and Primary School: A Qualitative Study on Teachers' Perception about Those Concepts. Creative Education, 12, 2505-2517.

https://doi.org/10.4236/ce.2021.1211187

Received: September 13, 2021

Accepted: November 7, 2021

Published: November 10, 2021

Copyright $\odot 2021$ by author(s) and Scientific Research Publishing Inc. This work is licensed under the Creative Commons Attribution International License (CC BY 4.0).

http://creativecommons.org/licenses/by/4.0/

\begin{abstract}
The objective of this study was to investigate ECEC teachers and primary school teachers' perspective about recognizing models, structures and using analogical thinking as a key to facilitate children's learning process. Without discussing in-depth the definition of a mathematical structure or model, teachers reflected about the possibilities and the reasons why to use models, structures and an analogical approach in teaching. Both ECEC teachers and primary school teachers showed a comprehension about those concepts, but mainly related to a theoretical approach. The idea that recognizing structures and models can help to identify what is known and what is new when we try to solve a problem has been discussed. An analogical approach that can help teachers to sustain children in the transition from what is known and what is not has been evaluated, connected to the zone of proximal development (Vygotsky) and to scaffolding (Bruner). Reflections about the Framework Plan for Kindergartens and the Framework for basic skills in primary school are reported. Both ECEC teachers and primary school teachers evaluated the concepts of "models" and "structures" as important, agreeing with Van Hiele and Bartha's definition. Both groups of teachers also recognized the importance of analogical thinking, where structures and models are useful for defining a starting point in the learning process.
\end{abstract}

\section{Keywords}

ECEC, Primary School, Analogical Thinking, Vygotsky, Structures, Models 


\section{Introduction}

The definition of the word "structure" (intended as mathematical structure) has been described as complicated (Van Hiele, 1986), also if it has been presented as an important concept for mathematics and for other disciplines (Benjamin, 2011; Dieudonné, 1982; Gandillac et al., 2015; Resnik, 1981, 1982). A possible definition is that a structure is an extremely general concept that in mathematics indicates a non-empty set in which one or more relations or correspondences that characterize it are defined (Corry, 1992). This concept can be considered similar to the meaning of the word "category", widely used as a fundamental element of knowledge in Bruner's theory (Bruner, 2006; Takaya, 2008). The understanding of mathematical structure is important for learning a scientific approach as modelling (Nguyen, 2000) or problem solving (Schoenfeld, 2014). Using a less precise approach but which opens for a greater generalization, the term "model" can be used instead of the term structure (Marker, 2006), so as to be able to relate this term to other subjects than mathematics (Byl, 2003; Giere, 2004; Weisberg, 2012). The importance of teaching to observe and understand models in nature and in life is a fundamental aspect of the process of knowledge and problem solving (Lesh \& Doerr, 2003) even if not deeply investigated in Early Childhood Education and Care (ECEC) and primary school.

Similarly, of great importance is the concept of analogical thinking. This term comes from the Greek avaloyia and from Latin analogia and can be considered as a comparison between two objects that highlight characteristics in which they are similar. Analogical reasoning means thinking that relies upon an analogy. An analogical argument is a representation of an analogical reasoning based on accepted similarities between two systems in order to support the conclusion that others similarities exist (Bartha, 2013). Despite having a mathematical origin, it is easily applied to other disciplines (Gentner \& Smith, 2012; Matlen et al., 2012; Sibley, 2009). Analogy has been defined as the core of cognition, and the ability to make analogies has been identified as the root of all our concept because it makes sense of the new and unknown in terms of the old and known (Hofstadter \& Sander, 2013). A similar description can be found in the symbolic representation described by Bruner (Ozdem-Yilmaz \& Bilican, 2020). Analogical thinking has been described as important in education for people with and without disabilities (Harrison \& Treagust, 2006; Vakil et al., 2011) as well as for developing higher-order thinking (Richland \& Begolli, 2016), also in ECEC children (Goddu et al., 2020; Thibaut \& Goldwater, 2017) and primary school children (Heywood \& Parker, 2009).

Research presents studies related to the usefulness of analogical approach in primary school (Heywood \& Parker, 1997) and upper-primary school (Maharaj-Sharma, 2011), but a specific study describing Norwegian teachers' perception regarding a didactical approach linked to models, structures or analogical thinking is missing in the literature. For this reason, this article aims to answer to the following research question: "What perception do ECEC teachers 
and primary school teachers have of the importance of using models, structures and analogical thinking in teaching?"

\section{Theoretical Framework}

The theoretical framework used for analysing teachers' perspective is based on four theories: two more related to mathematics (Van Hiele's definition of structure (Van Hiele, 1986) and Bartha's definition of analogical thinking (Bartha, 2013) and two more related to children's development (Vygotsky's Cognitive Development Theory (Vygotsky, 2012) and Bruner's learning theory (Bruner, 2006).

The first theory of the framework is related to Van Hiele's definition of structure. This definition is introduced in the description of how children learn geometric thinking (Van Hiele, 1986). Van Hiele presents this learning process as a discontinuous process, characterized by different levels of thinking. Those levels are sequential and invariant, and a progress through the levels is dependent on instruction and not on age. Those levels are five, but have been enriched by a basic one (Clements \& Battista, 1992). At the pre-recognitions level, children perceive geometric shapes by attending to only a part of the shape's characteristics and state that (they can recognize curvilinear from rectilinear, but not shapes in the same class). At the visual level, children judge figures by their appearance. Attributes or properties of shapes are not thought about. Determination of a shape is made in a global, holistic way. At the descriptive level, children understand and recognize shapes from their properties. Those properties are not logical ordered, anyway. At the informal deduction level, children can form abstract definitions, classify, and pose informal arguments to justify classifications. At the formal deduction level, students can create formal deductive proofs. At the rigor level, individuals can compare different axiomatic systems. This progression means that van Hiele wants to highlight how important is that children explore domains before describing them, or that they elaborate description in concrete before abstraction (Noddings, 1987). The concept of structure belongs to every level of thinking. A precise definition is not provided but it is considered as objective and therefore identifiable by all in the same way, once defined (Van Hiele, 1986: p. 27). Moreover, it can be extended and repeated, then it can be defined similar to a pattern (Van Hiele, 1986: s. 23).

The second theory is related to Bartha's definition of analogical thinking (Bartha, 2013). Analogical thinking is a type of thinking that relies on analogies, and this means on a comparison between two objects (or two situations) that have similar characteristics, although not completely identical to each other (Bartha, 2013). Analogies and analogical thinking have been recognized as a key in facilitating insight in order to design possible solutions to a problem (Bartha, 2013: p. 4). Developmental psychology (Goswami, 2013) indicates that the human mind, from early childhood, naturally passes through successive analogical stages. For example, a child uses objects that resemble each other as if they have the same 
properties, understands the relationship between similar shapes, or understands the difference between a whole and a part of it (according to a concept related to the analogy of proportion). This confirms that alongside logical thinking it is also important to analyse and observe the development of analogical thinking. In fact, it is known that the human brain is made up of two hemispheres that preside over two different modes of functioning: the left hemisphere can be defined as logical and rational, and intervenes in sequential and verbal processes and behaviours; the right hemisphere, on the other hand, is the analogical and intuitive hemisphere and intervenes above all in the recognition of complex visual images and in the mental representation of objects (Vitz, 2017).

In addition to the theories presented, there are two development theories on which this article is based.

Vygotsky's Cognitive Development Theory (Vygotsky, 2012) highlights how interactions with society can guide and construct children's cognitive abilities. Culture then can be considered as a mediator for enhancing specific abilities, such as learning, memory, attention, and problem solving. Vygotsky considers that culture-specific tools can have an important role in the way children organize and think about the world. These tools may include various social artifacts, such as books or technologies. Moreover, he describes signs (language, writing and counting) as a key for mediating cognitive development, defining the learning process as the internalization of these signs. Another important aspect of Vygotsky's theory is the Zone of Proximal Development. Vygotsky means that there is a disparity between what a child can perform independently and the potential learning that can be reached by the child with the assistance of an adult or through collaboration with peers. The role of the teacher (or the adult) or peers with more expertise is then sustain the child in the process of learning, as a transition through the zone of proximal development.

The fourth theory that defines the theoretical framework is Bruner's learning theory (Bruner, 2006). Bruner has been interested in the notion of how the environment (a set of values, skills, and ways of life) in which a person live can shape the mind. The person is endowed with innate mental structures that can be influenced by internal and external factors. The brain structure can therefore be defined as dynamic and the cognitive styles are different and individual. Each cognitive style determines an operational strategy linked to the context. Bruner considers cognition as a continuous integration between analytical thinking (logical discursive) and an intuitive one (symbolic or analogical). According to Bruner, the individual implements categorization processes to encode reality, linking new information to what is already known. An important aspect related to Bruner's theory is scaffolding, which is a set of helping strategies used by an expert to facilitate a child's learning process. The concept was used as a metaphor for the intervention of the expert who helps the less expert (the child) in solving a problem or a task that alone would not be able to complete. The experienced person can be an adult or a more experienced peer. In the educational 
context, when children receive the support they need in the initial phase of learning, it opens up to the possibility of using what has been learned at a later time, in an independent and effective way.

\section{Methodology}

The study involved 5 ECEC teachers (Lise, Marie, Rita, Jonas, Tor) and 5 primary school teachers (John, Lena, Siri, Mats, Elise) in Norway.

ECEC teachers were chosen in relation to their interest in mathematics and their connection with the University. All five had a degree in Early Childhood Teacher Education obtained after 2014, and two of them (Lise and Tor) obtained it after 2017.

Primary school teachers were chosen in relation to their interest in mathematics, and the fact that they were teaching mathematics in the primary school. All five had a degree in teacher education, with mathematics as one of the main subjects. Three of them (John, Mats and Siri) had obtained a specialization in mathematics after 2014.

The present study was conducted developing a one-to-one non-structured interview with both ECEC teachers and primary school teachers. The starting point for this interview was based on specific keywords (model, mathematical structure, analogical thinking) and a question ("Have you ever referred to situations that the child has known to help him cope with a similar new activity?"). Those terms were presented to teachers and they reported their perception and reflections about those concepts.

This has been applied both with ECEC teachers and primary school teachers.

The duration of the interview was very variable, linked to the interviewee's desire to deepen the subject during the dialogue or to the knowledge that the teacher already had about the subject. The average duration was 20 minutes.

The ECEC teachers varied from age 30 to 41 , where two were male, and three were female. The primary school teachers varied from age 32 to 49 , where two of the participants were male, and three were female.

The interviews were not recorded but the most important concepts were noted and immediately reconstructed by the researchers. Subsequently, the researchers discussed the transcribed notes with the interviewed teachers, to check the accordance between the will of the interviewed teachers and the meaning of what was reported. This was done both in Norwegian (the original language for interviews) and in English. Transcripts were immediately anonymised, and no personal data were collected. Teachers' names were changed to ensure anonymity.

The qualitative analysis of both ECEC teachers and primary school teachers' interviews was based on the theoretical framework previously described. In addition, it has been done a reference to the Framework plan for kindergartens (Norwegian Directorate for Education and Training, 2017) for the interviews conducted with ECEC teachers, and to Framework for basic skills in primary school (Norwegian Directorate for Education and Training, 2020) for the inter- 
views conducted with primary school teachers.

\section{Results}

\subsection{ECEC Teachers about Models and Structures}

The first part of the non-structured interview was based on an open discussion regarding words "structure" and "models". All ECEC teachers understood the use of the term "model", described as " $A$ figure, a behavior, that can be imitated" and " $A$ less detailed definition of something that can be reproduced". They didn't consider this word as specifically related to mathematics.

With regard to the term "structure", on the other hand, three teachers wondered if it was necessary to link it to mathematical concepts " Are you talking about mathematical structure?" or "Structure means something as ... to define a shape?") or to engineering ("Structure as to build a scaffolding?"). The fourth teacher (Tor) defined it as "something that has to be created or defined for helping children to understand nature" and the fifth (Lise) as "Structures are everywhere. Our role is to identify them".

\subsection{ECEC Teachers about Analogical Thinking}

The longest discussion with all teachers has been about what does it means to approach education through analogical thinking.

Two teachers out of five tried to identify analogical, or more precisely analogic, as "what is not digital" " Analogic means practical", "The real World is analogic"). After a brief discussion about the concept of analogical thinking and about the learning process in general, other explanations were presented: "If we want to sustain children in their learning process, it is important to start from what they already know. For this reason, I understand that an analogical approach can be usefur". Lisa said, "To be able to really surprise yourself with the children you have to sit down with them, stand next to them ... so ... you can look at what they want to discover, and you can say that it is possible to understand together how to get this knowledge".

A common idea was presented from all the ECEC teachers: children can understand how to decide, how to solve a problem, and the teacher's role is to sustain them in their learning process, showing a way without giving instructions. "My wish is that the children understand how to get from here to there.". "First, we see it together, then you do it alone. How do you know? Discover, try, investigate ..." "We can do it together. The child should not follow me, but he should build the path with me. We can identify relationships together". Tor said: "Every time that there is a problem, I suggest thinking about it, and to understand if it is like something that happened before, in order to understand how to proceed."

\subsection{Primary School Teachers about Models and Structures}

Also in this case all the non-structured interviews started with an open discussion regarding the words "structure" and "model". All the primary school teach- 
ers understood the word "model" and described it as " $A$ figure that could tell us something" and "Information structured and organized, so that it is easier to understand.". They did not consider the word to be specifically related to mathematical concepts, but as part of the mathematical language that is commonly used together with children. One teacher said that "We tell them to make a model, so that it is easier for them to understand the problem". One of the teachers said towards the end that "We can actually say that a model is a description of reality, which is used to explore".

When it came to the word "structure", the five teachers had different opinions regarding the words as directly linked to mathematics. "Do you mean structure, as in the structure of a moder? Or as in the structure of a symmetrical shape?". They also saw "a link to engineering in mathematics", as one of the teachers (John) said "Are you referring to some kind of structure in mathematics, like when we are building paper bridges, and talking about triangle structure in the shape?

\subsection{Primary School Teachers about Analogical Thinking}

Also in the non-structured interview with the primary school teachers, the longest time was used for discussing what does it mean to approach education through analogical thinking.

All the teachers started discussing about the learning process in general. One teacher said that "Our role is to guide the children towards new knowledge. We only act as a support". All the teachers quickly came to the conclusion that it is best that the children develop their own ideas, and that the teachers merely function as guides in the process. One teacher (Siri) said "If we want to guide the children to new knowledge, it can be smart to start with something they already have knowledge about. If you want to act as a guide for the children in search for knowledge, it is important that you sit down and talk with them, and start an open discussion in class, where they are able to express their knowledge, and learn from each other. The teacher's role in this environment is to support the children in their discussion". One teacher gave an example: "When we were starting to learn about multiplication, one child suddenly realized that multiplication actually is addition of the same number, multiple times. I could clearly see that he was grounded into his knowledge about addition, building further on it".

A common idea from all teachers was that it is important to start the learning process with something that the children already had knowledge about. One teacher (Elise) said that "When we were talking about what does it mean 360 degrees around a circle, one of the children had a hard time trying to understand this concept. I knew he was into snowboarding, and therefore I asked him how is called the movement of spinning a snowboard around in one circle. He answered three-sixty. Suddenly I could see a light turning on inside his eyes. So he asked if one half of a circle is 180 degrees, because half a turn in snowboarding is called a one-eighty, and he seemed satisfied". 
Another teacher said that "When you take into consideration what the children already know, and help them finding the link between the current problem and their existing knowledge, it is remarkable what they are able to learn". While another teacher in the interview said that "learning is a process, and I often say to the children that we have to learn together. Together we have to identify the problem, and find a solution". One of the teachers in the interview said that "analogical thinking is not just something we use in mathematics, but also in other subjects. If we have a conversation with students about international conflicts, I find easier to talk about it if I start the dialogue by giving them an example from the school yard, to make it more understandable."

Two of the teachers also saw a value in analogical thinking, regarding the children's own self-esteem. "We can clearly see that some of the children have being less active in the learning process because they do not think that they are able to understand. When this is the case, it is important to motivate the children, and show them that they are able to do it. One of the ways for involving them in the learning process, is by comparing a concept to something they already have knowledge about".

\section{Discussion}

\subsection{The Perception of Words "Structure" and "Model" in Education}

Regarding the ECEC teachers, the word "model" has been recognised as known and associated to a general description. This could be related to the fact that the word is presented in the Framework plan for kindergartens (Norwegian Directorate for Education and Training, 2017) as a general meaning, especially related to role model (Norwegian Directorate for Education and Training, 2017: p. 15, 24). A different understanding is showed in relation to the term "structure". In accordance to the fact that it doesn't exist a univocal definition of this term (Corry, 1992), it is possible perhaps to highlight a difference between those who received the degree before or after 2017. Two teachers who received their degree after 2017 showed a greater understanding of the term. A possible explanation could be related to the fact that the new edition of the Framework plan for kindergartens presents a more explicit reference to this term "This learning area is about discovering, exploring and creating structures and helps the children to understand relationships in nature, society and the universe. "(Norwegian Directorate for Education and Training, 2017: p. 53) and this can have determined a greater interest in this word already during studies. With a so small sample it is impossible to generalize this funding, but a discussion related to the importance of using precise terms in Framework plan for kindergartens can be raised. In fact, ECEC teachers show a deep knowledge of the content that are presented and explained in this official document.

Analysing the discussion reported with the theoretical framework, some interesting elements can be highlighted. The definitions of the concept "structure" and "model" presented by ECEC teachers can be related to the Van Hiele's de- 
scription of those terms (Van Hiele, 1986). In fact " $A$ behaviour that can be imitated" and "Something that can be reproduced" indicate an idea that is similar to a pattern (Van Hiele, 1986: s. 23). In addition, ECEC teachers affirm that "Structures are everywhere. Our role is to identify them". This recall the Van Hiele's idea of objectivity related to structures, so that everyone who is observing a situation can define a structure in a univocal way (Van Hiele, 1986: p. 27).

When it comes to primary school teachers, the word "model" is a central part of the core-elements in mathematics, stated in the National Curriculum from 2020 (Norwegian Directorate for Education and Training, 2020). The word model is described as a central part of the mathematical language, and a key tool in children's work with mathematics. The core-elements of mathematics states that one has to find, discuss and solve problems connected to mathematics, and that analysing and finding correct representations (models and structures) is a key element of this. Another key part of the core-elements is related to the role of the teachers, because it is highlighted that the students themselves have to discover connections and structures, without receiving them as stated facts and solutions.

Even though the reference document was published in 2020, teachers seem comfortable referring to the concepts described in it.

Referring now to the theoretical framework, it is possible to observe that also primary school teachers' perception about the concepts of model and structures seem related to Van Hiele's definition. In fact, the sentence "We can actually say that a model is a description of reality, which is used to explore" recalls Van Hiele's idea about the importance of exploring domains before describing them (Noddings, 1987). The sentence presented by John, instead, underlines as structure recalls to the mind a relation with geometry (Van Hiele, 1986).

\subsection{What Does It Means Analogical Thinking}

About teachers' perception of the importance of analogical thinking, common aspects can be highlighted comparing ECEC teachers opinions and primary school teachers ideas. This could be related to the fact that analogical thinking is presented as important both in the Framework plan for kindergartens (Norwegian Directorate for Education and Training, 2017) as well as in the Framework for basic skills in primary school (Norwegian Directorate for Education and Training, 2020). In fact, in the Framework plan for kindergartens, analogical thinking is identifiable through words as "relationships" (Norwegian Directorate for Education and Training, 2017: p. 8, 15, 19, 30,33) and "comparison" (Norwegian Directorate for Education and Training, 2017: p. 53), as well as "seeking solutions" (Norwegian Directorate for Education and Training, 2017: p. 53). In the same way it can be considered important for primary school, because the Framework for basic skills in primary school highlights as fundamental for learning concept as "searching for patterns" (Norwegian Directorate for Education and Training, 2020: p. 2), "finding relationships" (Norwegian Directorate for Education and 
Training, 2020: p. 2, 3), "analysing, rethinking and finding new ways of approaching known and unknown problems" (Norwegian Directorate for Education and Training, 2020: p. 2, 3).

Referring to the theoretical framework, other important concepts that can be highlighted in both ECEC teachers and primary school teachers reflections about analogical thinking are related to Bartha's definition (Bartha, 2013). In fact, Lise says that it is important "To stand next to them ... so ... you can look at what they want to discover, and you can say that it is possible to understand together how to get this knowledge". This recalls the concept of "insight" (Bartha, 2013). Similarly, the primary school teacher Elise describes the process of understanding as a real discovery obtained connecting theory and reality, following again a path comparable to insight. Moreover, a primary school teacher says "One of the ways for involving them in the learning process, is by comparing a concept to something they already have knowledge about' recalling Bartha's definition of analogical thinking as comparing (Bartha, 2013).

During the conversation developed about analogical thinking, a reference to Vygotsky's Cognitive Development Theory, and in particular to the Zone of Proximal Development can be identified, both in ECEC teachers' sentences as well as in primary school teachers' opinions. In fact Tor (ECEC teacher) says "Every time that there is a problem, I suggest thinking about it, and to understand if it is like something that happened before, in order to understand how to proceed". This can be seen as the zone between what a child can perform independently and the potential learning that can be reached by the child with the assistance of an adult or through collaboration with peers (Vygotsky, 2012). Similarly, Siri (primary school teacher) says "If we want to guide the children to new knowledge, it can be smart to start with some-thing they already have knowledge about. If you want to act as a guide for the children in search for knowledge, it is important that you sit down and talk with them, and start an open discussion in class, where they are able to express their knowledge, and learn from each other. The teacher's role in this environment is to support the children in their discussion". Primary school teachers however demonstrate a greater familiarity about discussing analogical thinking in a more general way. In fact, an example comes from a primary school teacher who generalizes the idea, and affirms that this approach can be used for example for building a conversation with children about any subject, for example international conflicts.

Analysing the conversations developed about analogical thinking both with ECEC teachers and primary school teachers, also a reference to Bruner's learning theory (Bruner, 2006) can be done. In particular, teachers reflect about the importance of sustaining children's learning process through analogical thinking. An ECEC teacher affirms that "We can identify relationships together" and this can clearly be related to scaffolding as a set of help strategies used by an expert to facilitate a child's learning process. Similarly a primary school teacher says that "Our role is to guide the children towards new knowledge. We only act as a 
support" presenting again the idea of scaffolding.

\section{Conclusion}

In the reflections generated during the one-to-one non-structured interviews, both ECEC teachers and primary school teachers evaluated the concepts "models" and "structures" as important, confirming and proposing terms that agree with Van Hiele and Bartha's definitions. In addition, both ECEC teachers and primary school teachers described those concepts through words that highlighted a connection with the theories of learning. In fact, "model" and "structure" have been evaluated by both ECEC teachers and primary school teachers as useful elements for defining the starting point of the learning process: these concepts in fact have been considered as a key for identifying what the children know, in accordance with Vygotsky's theory.

The use of analogical reasoning also aroused interest both in ECEC teachers and in primary school teachers. Teachers in fact spoke about it using key words that could be connected with the zone of proximal development, as well as with scaffolding. This indicates that they identified a connection between an analogical approach and the learning theories of Bruner and Vygotsky.

Additionally, the research highlighted two interesting aspects that would require further research. The first one is that it has been highlighted how complex it is to relate the use of the concepts "model", "structure" and "analogical thinking" to practice. It could then be useful to introduce practical examples about these in the university courses, in order to prepare the future ECEC teachers and primary school teachers in becoming familiar with these concepts. The second one is that primary school teachers have shown greater familiarity in the use of specific words as model or structure. According to the researchers, this could be due to the fact that these terms are presented in the Framework for basic skills in primary school more clearly and explicitly. It could be interesting to reflect about the possibility of introducing in the Framework plan for kindergartens a more specific reference to those terms. This could be realized with the aim of making even clearer that the learning process is a path which begins in kindergarten and develops through school, as a progression that should be as uniform and connected as possible.

\section{Acknowledgements}

We would like to thank all ECEC teachers and primary school teachers that have been involved in the project.

\section{Conflicts of Interest}

The authors declare no conflicts of interest regarding the publication of this paper.

\section{References}

Bartha, P. (2013). Analogy and Analogical Reasoning. In E. N. Zalta (Ed.), The Stanford 
Encyclopedia of Philosophy (Spring 2019 Edition) (P. 80). Metaphysics Research Lab, Stanford University.

https://plato.stanford.edu/archives/spr2019/entries/reasoning-analogy/

Benjamin, B. (2011). Jean Piaget-Le structuralisme (1968). Publications Pimido.

Bruner, J. S. (2006). In Search of Pedagogy Volume I: The Selected Works of Jerome Bruner, 1957-1978. Routledge. https://doi.org/10.4324/9780203088609

Byl, J. (2003). Mathematical Models \& Reality. In Proceedings of the 2003 Conference on Association of Christians in the Mathematical Sciences (pp. 33-48). Langley, BC, Canada. https://pillars.taylor.edu/acms-2003/11/

Clements, D. H., \& Battista, M. T. (1992). Geometry and Spatial Reasoning. In Handbook of Research on Mathematics Teaching and Learning (pp. 420-464). Macmillan Library Reference.

Corry, L. (1992). Nicolas Bourbaki and the Concept of Mathematical Structure. Synthese, 92, 315-348. http://www.jstor.org/stable/20117057

https://doi.org/10.1007/BF00414286

Dieudonné, J. (1982). The Work of Bourbaki during the Last Thirty Years. Notices of the American Mathematical Society, 29, 618-623.

Gandillac, M., Goldmann, L., \& Piaget, J. (2015). Entretiens sur les notions de genèse et de structure (Vol. 9). Walter de Gruyter GmbH \& Co KG.

Gentner, D., \& Smith, L. (2012). Analogical Reasoning. In Encyclopedia of Human Behavior (2nd ed., pp. 130-136). Elsevier.

https://doi.org/10.1016/B978-0-12-375000-6.00022-7

Giere, R. N. (2004). How Models Are Used to Represent Reality. Philosophy of Science, 71, 742-752. https://doi.org/10.1086/425063

Goddu, M. K., Lombrozo, T., \& Gopnik, A. (2020). Transformations and Transfer: Preschool Children Understand Abstract Relations and Reason Analogically in a Causal Task. Child Development, 91, 1898-1915. https://doi.org/10.1111/cdev.13412

Goswami, U. (2013). Analogical Reasoning in Children. Psychology Press.

Harrison, A. G., \& Treagust, D. F. (2006). Teaching and Learning with Analogies. In $\mathrm{Me}$ taphor and Analogy in Science Education (pp. 11-24). Springer. https://doi.org/10.4324/9781315804729

Heywood, D., \& Parker, J. (1997). Confronting the Analogy: Primary Teachers Exploring the Usefulness of Analogies in the Teaching and Learning of Electricity. International Journal of Science Education, 19, 869-885. https://doi.org/10.1080/0950069970190801

Heywood, D., \& Parker, J. (2009). The Role of Analogies in Learning. In The Pedagogy of Physical Science (pp. 39-64). Springer. https://doi.org/10.1007/978-1-4020-5271-2 3

Hofstadter, D., \& Sander, E. (2013). L'analogie, cour de la pensée. Odile Jacob. https://doi.org/10.3917/sh.dorti.2014.01.0354

Lesh, R. E., \& Doerr, H. M. (2003). Beyond Constructivism: Models and Modeling Perspectives on Mathematics Problem Solving, Learning, and Teaching. Lawrence Erlbaum Associates Publishers. https://doi.org/10.4324/9781410607713

Maharaj-Sharma, R. (2011). An Examination of Types and Usefulness of Analogies Generated by Upper Primary School Students-A Case Study.

Marker, D. (2006). Model Theory: An Introduction (Vol. 217). Springer Science \& Business Media.

Matlen, B. J., Atit, K., Göksun, T., Rau, M. A., \& Ptouchkina, M. (2012). Representing Space: Exploring the Relationship between Gesturing and Geoscience Understanding 
in Children. In International Conference on Spatial Cognition (pp. 405-415). Springer. https://doi.org/10.1007/978-3-642-32732-2 26

Nguyen, H. T. (2000). Some Mathematical Structures for Computational Information. Information Sciences, 128, 67-89. https://doi.org/10.1016/S0020-0255(00)00039-6

Noddings, N. (1987). The World's a Stage. Journal for Research in Mathematics Education, 18, 5. https://doi.org/10.2307/749088

Norwegian Directorate for Education and Training (2017). Framework plan for kindergartens.

https://www.udir.no/globalassets/filer/barnehage/rammeplan/framework-plan-for-kin dergartens2-2017.pdf

Norwegian Directorate for Education and Training (2020). Læreplan i matematikk fellesfag $2 P-Y-V g 3$ påbygging til generell studiekompetanse.

Ozdem-Yilmaz, Y., \& Bilican, K. (2020). Discovery Learning-Jerome Bruner. In Science Education in Theory and Practice (pp. 177-190). Springer.

https://doi.org/10.1007/978-3-030-43620-9 13

Resnik, M. D. (1981). Mathematics as a Science of Patterns: Ontology and Reference. Nous, 14, 529-550. https://doi.org/10.2307/2214851

Resnik, M. D. (1982). Mathematics as a Science of Patterns: Epistemology. Nous, 16, 95-105. https://doi.org/10.2307/2215419

Richland, L. E., \& Begolli, K. N. (2016). Analogy and Higher Order Thinking: Learning Mathematics as an Example. Policy Insights from the Behavioral and Brain Sciences, 3, 160-168. https://doi.org/10.1177/2372732216629795

Schoenfeld, A. H. (2014). Mathematical Problem Solving. Academic Press.

Sibley, D. F. (2009). A Cognitive Framework for Reasoning with Scientific Models. Journal of Geoscience Education, 57, 255-263. https://doi.org/10.5408/1.3559672

Takaya, K. (2008). Jerome Bruner's Theory of Education: From Early Bruner to Later Bruner. Interchange, 39, 1-19. https://doi.org/10.1007/s10780-008-9039-2

Thibaut, J. P., \& Goldwater, M. B. (2017). Generalizing Relations during Analogical Problem Solving in Preschool Children: Does Blocked or Interleaved Training Improve Performance? In Proceedings of the 39th Annual Meeting of the Cognitive Science So$\operatorname{ciety}($ p. 6). Austin, TX.

Vakil, E., Lifshitz, H., Tzuriel, D., Weiss, I., \& Arzuoan, Y. (2011). Analogies Solving by Individuals with and without Intellectual Disability: Different Cognitive Patterns as Indicated by Eye Movements. Research in Developmental Disabilities, 32, 846-856. https://doi.org/10.1016/j.ridd.2010.08.006

Van Hiele, P. M. (1986). Structure and Insight: A Theory of Mathematics Education. Academic Press.

Vitz, P. C. (2017). The Origin of Consciousness in the Integration of Analog (Right Hemisphere) \& Digital (Left Hemisphere) Codes. Journal of Consciousness Exploration \& Research, 8, 881-906.

Vygotsky, L. S. (2012). The Collected Works of LS Vygotsky: Scientific Legacy. Springer Science \& Business Media.

Weisberg, M. (2012). Simulation and Similarity: Using Models to Understand the World. Oxford University Press. https://doi.org/10.1093/acprof:oso/9780199933662.001.0001 